\title{
ECONOMIC STRUCTURE AND ENERGY SAVINGS FROM ENERGY EFFICIENCY IN HOUSEHOLDS
}

\author{
Jaume Freire-González ${ }^{1,2}$ \\ David Font Vivanco 3 \\ Ignasi Puig-Ventosa ${ }^{2}$
}

${ }^{1}$ Department of Economics, Harvard University, Cambridge, Massachusetts 02138, United States.

${ }^{2}$ ENT Environment and Management, Sant Joan, 39, 1, 08800 Vilanova i la Geltrú, Barcelona, Spain.

${ }^{3}$ Center for Industrial Ecology, School of Forestry and Environmental Studies, Yale University, New Haven, Connecticut 06511, United States.

\begin{abstract}
When an energy efficiency improvement occurs at the household level, several mechanisms, grouped under the name of the rebound effect, increase the available income and consumption, increasing the total energy consumption of the economic structure. The present research analyses the links between energy efficiency improvements in households, consumption, and the economic structure in an input-output framework. We examine, from an empirical perspective, the relationship between energy efficiency improvements and the economic structure, and between the direct and the indirect rebound effect. The limits of the input-output methodology in assessing the direct and indirect rebound effect have been empirically tested with respect to efficiency improvements of electricity uses in households in Catalonia.
\end{abstract}

\section{Keywords}

Input-output analysis; Rebound effect; Energy economics; Energy efficiency; Structural analysis. 


\section{INTRODUCTION}

Technological progress has traditionally been the favoured solution to the problem of the increasing use of resources by the economy (Kemp, 1994; von Weizsäcker, 1994; Hinterberger and Schmidt-Bleek, 1999; Lovins and Lovins, 2001; Grubler, 2003). The underlying rationale is that the development of more resource-efficient technologies makes it possible to sustain the same level of material welfare using less resources, because it improves the productivity of factors, resources, and processes. Although this is an irrefutable fact within a technical-engineering framework, there are doubts about its validity at other levels of analysis, such as the socioeconomic level. Indeed, there is a body of literature that provides empirical evidence for the fact that, while efficiency improvements in resource use have been continuous since early capitalism, the global consumption of resources such as energy has not stopped growing (Herring, 1999; Ayres et al., 2003; Fouquet and Pearson, 2006).

The relation between new energy-saving technological developments and sustainable consumption can be addressed from different perspectives. One of them is to consider the effects of changes in consumption patterns and the consequent effects on resource consumption in the economy when an energy efficiency improvement causes a change in disposable income. For instance, the case of energy efficiency improvements in household appliances leading to reductions in the unitary costs of the provided energy services (e.g. cost per cloth load of a washing machine). Along these lines, some authors have considered the effects from the respending of the additional disposable income within the so-called rebound effect framework (Jalas, 2002; Carlsson-Kanyama et al., 2005; Cohen et al., 2005; Takase et al., 2005; Mizobuchi, K., 2008, Nässén and Holmberg, 2009; Druckman et al., 2010; Thomas, 2011; Saunders and Tsao, 2012; Thomas and Azevedo, 2013a; Thomas and Azevedo, 2013b; Chitnis et al., 2013; Yu et al., 2013; Font Vivanco et al., 2014). 
The rebound effect can be defined as the reduction in the potential or engineering energy savings resulting from technological improvements in the efficiency of providing an energy service (Wigley, 1997). That is, the difference between the initial expected energy savings from an efficiency improvement and the final consumption of energy. The rebound effect has mainly been discussed with respect to energy uses and analysed from different scopes and economic levels (Lovins, 1977; Brookes, 1979; Khazzoom, 1980; Saunders, 1992; Greening et al., 2000; Sorrell, 2007; Freire-González, 2010; Wang et al., 2012).

Most of the literature on the rebound effect has been oriented toward obtaining new empirical evidence (Ruzzenenti and Basosi, 2008). Saunders (2008) conducted a theoretical analysis of how the choice of production functions can inadvertently pre-determine results. According to the author, the Leontief function exhibits zero rebound when there is an improvement in energy efficiency of productive sectors. The aim of this paper is to analyse from an empirical perspective how the configuration of the economic structure affects the magnitude of the indirect rebound effect derived from energy efficiency improvements in households in a Leontief's framework. This is done by demonstrating the importance of the direct rebound effect over the indirect rebound effect. ${ }^{1}$ Then, extreme scenarios are empirically tested to set the structural limits of the direct plus indirect rebound effects for a specific economic structure specified through Leontief production functions. Specifically, these scenarios have been applied to the case of efficiency improvements of electricity uses in households in Catalonia. This research deepens our understanding of the relationship between energy-saving technological change and sustainable consumption through the use of energy input-output analysis and re-spending analysis.

The theoretical framework and empirical contribution of this research is aligned with previous work conducted by Druckman et al. (2010), Freire-González (2011), and Thomas and Azevedo (2013a, 2013b), and particularly with the framework developed by Freire-González (2011).

\footnotetext{
${ }^{1}$ For definitions see section 2.
} 
Druckman et al. (2010) does a related analysis based on exogenous behavioural changes, but not endogenous changes in energy efficiency improvements in households. Thomas and Azevedo (2013a, 2013b) perform an interesting application of the two first methodologies applied to the US context.

The model is applied to Catalonia for the year 2005. This analysis derives from a deeper analysis of the direct and indirect rebound effect derived from Freire-González (2011). The structure of the paper is as follows: section 2 contains a literature review, in order to contextualize the issue; section 3 explains theoretical and methodological aspects related to final consumption in households and total energy consumption in the economy; section 4 characterizes the re-spending model by setting extreme scenarios to establish boundaries to the total energy use from technological improvements; section 5 shows the data and the results from the empirical simulations. Section 6 presents the main conclusions.

\section{THE INDIRECT REBOUND EFFECT AND THE ECONOMIC STRUCTURE IN THE LITERATURE}

The effects on energy consumption from the introduction of new energy-saving technologies in households have mostly been addressed from a static and direct perspective. Many empirical studies have estimated the direct rebound effect, defined as the increase in the demand of an energy service after the initial cost reductions caused by an energy efficiency improvement (Herring, 1999; Nesbakken, 2001; Guertin et al., 2003; West, 2004; Frondel et al., 2007; Davis, 2007). However, fewer studies have analysed the indirect rebound effect from an empirical 
perspective (Chitnis et al., 2012), i.e. the income and substitution effects ${ }^{2}$ on the overall consumption basket induced by changes in disposable income from an energy efficiency improvement. Indirect rebound effects are those microeconomic effects produced in the shortand middle-term from an energy efficiency improvement that the direct rebound effect does not take into account. Whereas the direct rebound effect represents the increase in the demand of the energy service that was subject to an energy efficiency improvement, the indirect rebound effect represents the increase in the energy consumption needed to satisfy the increased demand for other goods and services (Alfredsson, 2004; Druckman et al., 2010; Freire-González, 2011). The present research is framed in the context of the study of indirect rebound effects. Another perspective, which is outside the scope of this research, addresses rebound effects from a macroeconomic perspective, through which it is possible to study macroeconomic and long-term effects (e.g. market price and growth effects), which can be used to provide insights for policymakers in relation to global and complex issues such as energy supply and climate change (Jevons, 1865; Brookes, 1979; Saunders, 1992; Jenkins et al., 2011).

An important distinction to be made in the context of indirect rebound effects relates to the scope adopted when accounting for energy use; that is, whether only direct or embodied (or, alternatively, life cycle) energy use should be considered. With regards to this issue, a number of studies have estimated the energy content of the measures that lead to improved energy efficiency, mainly for domestic uses (Kaufmann and Azary-Lee, 1990; Feist, 1996; Winther and Hestnes, 1999; Casals, 2006; Royal Commission on Environmental Pollution, 2007; Sartori and Hestnes, 2007; Chitnis et al., 2013; Cellura et al., 2013). This approach to the indirect rebound effect is thus specific for each energy service. Furthermore, some authors argue that the embodied energy of the additional goods and services consumed constitutes an additional component of the indirect

\footnotetext{
${ }^{2}$ The income effect relates to the change in the demand for a product (good or service) due to a change in the consumers' real income, while the substitution effect describes the change in demand due to a change in the relative price (relative to other products), controlling for the change in real income.
} 
effect, in the form of the so-called "embodied energy" effect (Sorrell, 2007; van den Bergh, 2011). However, such considerations have been challenged by some authors (Murray, 2013; Font Vivanco and van der Voet, 2014), who have argued that the amount of energy use in upstream and downstream processes is the result of technological aspects rather than behavioural responses. Consequently, it is not appropriate to further decompose the indirect effect when an embodied or life cycle scope is adopted. Estimates of the embodied energy content of specific as well as general categories of goods and services can be obtained by means of environmentally-extended inputoutput analysis (EEIOA), life cycle assessment (LCA), or combinations of both in the form of hybrid LCA (Chapman, 1974; Herendeen and Tanaka, 1976; Kok et al., 2006; Joshi, 1999; Suh and Huppes, 2005).

In several studies, the empirical evidence of the rebound effect in the macroeconomic context was focused on the income effect caused by the introduction of efficiency improvements in energy services. This increase in disposable income stimulates consumption and associated energy demand. Some authors have used this interpretation, including Jalas (2002), Carlsson-Kanyama et al. (2005), Cohen et al. (2005), Takase et al. (2005), Druckman et al. (2010), and FreireGonzález (2011). Druckman et al. (2010) relate the changes in consumption patterns in households to the rebound effect. Using a quasi-multi-regional EEIOA model for the UK economy, they simulated the effects on greenhouse gas emissions from changing consumption patterns of households due to certain voluntary energy saving measures. Specifically, they estimated the re-spending effect of these actions. They found an indirect rebound effect of between $12 \%$ and $512 \%$, with a most likely estimation of $34 \%$, depending on the re-spending sectors. Another study for the UK (Chitnis et al., 2013), using a similar methodology, estimates the combined direct and indirect rebound effects from seven measures that improve the energy efficiency of UK dwellings in terms of greenhouse gases (GHG). Moreover, Thomas and Azevedo (2013a, 2013b) analyse the direct and indirect rebound effects for US households, also using an EEIOA approach. They obtained a rebound of 5-15\% for primary energy and $\mathrm{CO}_{2}$ emissions, 
assuming a 10\% direct rebound effect. They also obtained an indirect rebound effect of 30-40\% for $\mathrm{NO}_{\mathrm{x}}$ and $\mathrm{SO}_{2}$ emissions due to the increased efficiency in providing natural gas services.

Several authors have claimed that the indirect rebound effect caused by energy efficiency improvements is relatively small (Lovins et al., 1988; Greening and Greene, 1998; Schipper and Grubb, 2000; Dimitropoulos, 2007), owing to direct energy consumption making up a small part of total household expenditure. Adding to this, Greening and Greene (1998) argue that, for the vast majority of goods and services, the available data from input-output tables suggest that energy expenditure would be less than $15 \%$ of the total on average. However, other authors (Murray, 2013; Sorrell, 2007) have pointed out that the consideration of the embodied energy of products can notably increase indirect rebound effect estimates. Furthermore, Font Vivanco and van der Voet (2014) describe systematically larger rebound estimates from those studies applying a life cycle perspective.

\section{CHANGES IN ENERGY CONSUMPTION FROM CHANGES IN FINAL CONSUMPTION PATTERNS}

From a static perspective, without considering changes to the economic structure - that is, neither the trading relations amongst sectors (reflected in the technical coefficients), nor prices or total incomes - the indirect rebound effect can be estimated through the change in energy consumption necessary to satisfy the new final consumption pattern resulting from a given energy efficiency improvement.

In this context, a methodology combining an energy input-output analysis with a re-spending model can be useful for approximating the direct plus indirect rebound effect in terms of energy consumption in households (Alfredsson, 2004; Druckman et al., 2010; Freire-González, 2011). The following models can be reapplied for other economies if the required data is available. 
The energy input-output model assumes the following approach: ${ }^{3}$ let $e$ be a vector of direct sectorial consumption of different sources of energy - or the vector of direct sectorial electricity consumption in our case -, which is necessary for the production of goods in a productive system, and let $x$ be the vector of sectorial production. Then a vector of sector intensities in the use of energy can be calculated:

$$
w=e x^{-1}
$$

Where $w$ represents a set of coefficients of energy intensities, whose element $w_{i}$ represents the energy consumption required for the production of a monetary unit of good $i$. From equation (1):

$$
e=w x
$$

Moreover, the Leontief model can be expressed as: ${ }^{4}$

$$
x=(I-A)^{-1} y
$$

Where the expression $(I-A)^{-1}$ is the Leontief inverse matrix. Each element of the matrix $A$ represents a technical coefficient: $a_{i j}={ }^{x_{i j}} / x_{j}$; where $x_{i j}$ is the production of sector $i$ distributed to sector $j$, and $x_{j}$ is the total production of sector $j . y$ represents the vector of sectorial final demand. If $x$ in (2) is substituted by its value in (3), then:

\footnotetext{
${ }^{3}$ The model is based on previous developments from: Leontief (1970), Leontief and Ford (1971), Chapman (1974), Bullard and Herendeen (1975), Casler and Wilbur (1984), Proops (1988), Alcántara (1995), Lenzen et al. (2004).

${ }^{4}$ For more information on the development of the Leontief model, see Miller and Blair (2009).
} 


$$
e=w(I-A)^{-1} y
$$

In this case, $w(I-A)^{-1}$ is a lineal operator, which transforms final demand into energy consumption. This model obtains, under certain circumstances, the total energy consumption (direct plus indirect) that the overall economic system requires due to a change in the final demand from one or more economic sectors. Thus, this equation allows for the estimation of the indirect rebound effect, when there is a change in the final consumption pattern due to an improvement in energy efficiency. We assume it is a closed model with no imports. ${ }^{5}$

Some structural indicators can be obtained from this analysis, in order to identify which economic sectors have a specific influence in the economy.

The linear operator of (4) can be isolated and named $F$ :

$$
F=w(I-A)^{-1}
$$

Every element of this matrix $\left(F_{i j}\right)$ represents the additional energy consumption of sector $i$ due to a unitary increase in the final demand of sector $j$, including the direct plus indirect effects and shows the potential of sector $j$ in distributing the energy consumption throughout the economy.

\footnotetext{
${ }^{5}$ Although the Catalan economy is quite open in terms of energy consumption (Carpintero et al., 2015), the assumption that the model is closed is adopted not only for the purpose of simplicity, but also because although this could affect the specific values of energy intensity coefficients, we believe that it does not affect the main conclusions of this research.
} 
Finally, the final effect on energy consumption in all sectors from an increase of one unit to the final demand in sector $j$ is given by the sum of the elements of column $j$ of the Leontief Inverse matrix, multiplied by the energy intensities coefficients. This is analogous to the Leontief demand model, and measures the backward linkage coefficients in terms of energy consumption:

$$
F_{g i}=\sum_{i=1}^{n} W_{i} \alpha_{i j}
$$

where $w_{i}$ represents the energy intensity coefficients and $\alpha_{i j}$ the elements of the Leontief Inverse matrix. Those are the backward linkage coefficients in the consumption of energy. They will be relevant when considering the magnitude of the direct plus indirect rebound effect, as will be shown.

\section{MODELLING RE-SPENDING FOR A STRUCTURAL ANALYSIS}

It is possible to calculate the monetary savings due to energy efficiency improvements and then consider the re-spending effect of this increased disposable income. Moreover, there are several possibilities with respect to allocating the new disposable income and conceiving new consumption patterns for households, which need different amounts of total energy consumption to be produced. This section addresses how different allocation possibilities for these savings are related to different indirect rebound effects for a given economic structure.

Section 4.2 outlines the development of a re-spending model and the construction of extreme scenarios in total energy consumption. These scenarios are useful for establishing boundaries to the direct plus indirect rebound effect for the economy and for analysing the structural relationships between an economy and the rebound effect through final consumption patterns. 


\subsection{Modelling re-spending}

From Freire-González (2011), the households' budget in equilibrium can be expressed by isolating the new spending on electricity from other goods and services and assuming that income, energy price, and savings remain constant:

$$
y=x_{E} p_{E}+\sum_{i=1}^{n} x_{i} p_{i}+s
$$

Where $y$ is income, $x_{E} p_{E}$ represents the quantity and price of energy, $x_{i} p_{i}$ represents the consumption pattern (quantity and price of each good and service) and $s$ represents savings. In order to obtain new consumption patterns $\left(x_{i}^{\prime} p_{i}\right)$, expression (7) can also be expressed as:

$$
\sum_{i=1}^{n} x_{i}^{\prime} p_{i}=y-x^{\prime}{ }_{E} p_{E}-s
$$

And, from this expression:

$$
\sum_{i=1}^{n} x_{i}^{\prime} p_{i}=y-\left(1+\frac{\Delta x_{E}}{x_{E}}\right) x_{E} p_{E}-s
$$

Under certain hypotheses, the direct rebound effect from an energy service can be obtained from the price elasticity of energy demand (Khazzoom, 1980; Berkhout et al., 2000; Binswanger, 2001; Greene et al., 1999):

$$
\vartheta_{\varepsilon}(E)=-\vartheta_{p_{s}}\left(x_{s}\right)-1
$$

Where $\vartheta_{\varepsilon}(E)$ is the elasticity efficiency for energy demand and $\vartheta_{p_{s}}\left(x_{s}\right)$ is the elasticity price for the demand of an energy service. The own price elasticity of energy demand represents the 
percentage change of the energy demand after a change in the energy price. This can be estimated using several methods - with econometric estimates being the most commonly used, because they offer robust analyses and flexible data requirements. A distinction can be made between shortterm and long-term elasticities. Short-term usually refers to specific changes produced over one year. These elasticities usually show low values, as consumers have little reaction capacity in the short-term. Long-term elasticities represent longer periods, and have higher values, as demand can adapt to the new prices.

Considering that the definition of the rebound effect is:

$$
\begin{aligned}
& \vartheta_{\varepsilon}(E)=\frac{\Delta x_{E}}{\Delta \varepsilon} \frac{\varepsilon}{x_{E}} \\
& \frac{\Delta x_{E}}{x_{E}}=\vartheta_{\varepsilon}(E) \frac{\Delta \varepsilon}{\varepsilon}
\end{aligned}
$$

where $\varepsilon$ is energy efficiency. Introducing (12) inside (9), and substituting the efficiency elasticity of the energy demand in (10), the following expression is obtained:

$$
\sum_{i=1}^{n} x_{i}^{\prime} p_{i}=y-\left[1+\left(-\vartheta_{p_{s}}\left(x_{s}\right)-1\right) \frac{\Delta \varepsilon}{\varepsilon}\right] x_{E} p_{E}-s
$$

This expression allows for the construction of re-spending scenarios from the direct rebound effect estimations.

\subsection{Extreme scenarios}

This section develops specific extreme scenarios that will establish upper and lower limits to the direct plus indirect rebound effect in order to facilitate a structural and a more general analysis 
concerning energy efficiency improvements in households, consumption patterns, and the economic structure. These scenarios will facilitate, on the one hand, a structural analysis of the relationship between the rebound effect and the economic structure, and on the other hand, an analysis of the relationships between the direct and indirect rebound effect.

A. Worst-case scenario (W): This scenario considers what would happen in the worst case scenario, i.e., if all the monetary savings achieved by improving energy efficiency were entirely allocated to the acquisition of goods or services with the highest backward linkage coefficient in the consumption of energy $F_{g i}$.

The new final demand of the energy service that has improved its efficiency can be defined as:

$$
x_{E}^{w} p_{E}=\left[1+\left(-\vartheta_{p_{s}}\left(x_{s}\right)-1\right) \frac{\Delta \varepsilon}{\varepsilon}\right] x_{E} p_{E}
$$

For the sector with the highest $F_{g i}$ :

$$
x_{j}^{w} p_{j}=x_{j} p_{j}+x_{E}^{w} p_{E}=x_{j} p_{j}+\left[1+\left(-\vartheta_{p_{s}}\left(x_{s}\right)-1\right) \frac{\Delta \varepsilon}{\varepsilon}\right] x_{E} p_{E}
$$

The money spent in all sectors except for the electricity sector and for the one with the highest $F_{g i}$ would be:

$$
x_{i-j}^{w} p_{i-j}=x_{i-j} p_{i-j}
$$

$x_{j}$ being the sector with the highest backward linkage coefficient in energy consumption. 
B. Best-case scenario (B): This scenario considers what would happen in the best case scenario, i.e., if all the monetary savings achieved by improving energy efficiency were entirely allocated to the consumption of the good or service with the lowest backward linkage coefficient in energy consumption $F_{g z}$.

The new final demand of the energy service that has improved its efficiency can be defined as:

$$
x_{E}^{b} p_{E}=\left[1+\left(-\vartheta_{p_{s}}\left(x_{S}\right)-1\right) \frac{\Delta \varepsilon}{\varepsilon}\right] x_{E} p_{E}
$$

For the sector with the lowest $F_{g i}$ :

$$
x_{z}^{b} p_{z}=x_{z} p_{z}+x_{E}^{b} p_{E}=x_{z} p_{z}+\left[1+\left(-\vartheta_{p_{s}}\left(x_{s}\right)-1\right) \frac{\Delta \varepsilon}{\varepsilon}\right] x_{E} p_{E}
$$

For all sectors except electricity and also except the one with the lowest $F_{g i}$ :

$$
x_{i-z}^{b} p_{i-z}=x_{i-z} p_{i-z}
$$

$x_{z}$ being the sector with the lowest backward linkage coefficient in energy consumption.

The best and the worst-case scenarios determine the lower and the upper limits, respectively, of the indirect rebound effect in households, given a particular economic structure and price elasticity of demand for an energy service. Those limits are useful for understanding some structural questions; but it is unrealistic to think that under normal conditions these scenarios would occur at the macroeconomic level, as households' budgets are diversified in real economies. However, they are possible at the microeconomic level for certain products and services, under certain circumstances. 


\section{DATA AND RESULTS}

This section conducts an in-depth analysis of the extreme scenarios. As mentioned, these scenarios do not represent a realistic estimate of what would happen on a macroeconomic level. However, a detailed analysis of the results provided by these scenarios points to some key findings, as well as the possibility of drawing more general conclusions about the relationship between an economy and the rebound effect in households, or energy-efficiency technological progress in final consumer and energy consumption. At this point, it is important to note that a greater disaggregation in the input-output tables used in developing the model would lead to even more extreme results.

The empirical application of extreme scenarios was developed for electricity uses in households in Catalonia, and was based on work by Freire-González (2011). For purposes of its development, data for the period 2000-2008 on the annual electricity consumption by economic sectors in Catalonia was obtained from statistics and energy balances of the Ministry of Industry, Tourism and Commerce of Spain (see Table 1). The input-output tables for Catalonia for 2005 (TIOC-05) (Idescat, 2007) were also used. ${ }^{6}$

From the input-output tables, the backward linkage coefficients in terms of energy consumption were calculated to determine the direct plus indirect rebound effect, based on the new distribution of the final expenditure of households or the new pattern of final consumption. Therefore, the rebound effect will be of greater or lesser importance, depending on the backward linkage

\footnotetext{
${ }^{6}$ These were the most recent input-output tables for Catalonia at the time this research was conducted. Since then, the economic structure may have changed. However, results would not be significantly affected using more recent tables.
} 
coefficient in terms of energy of the energy sector, relative to the rest of the sectors (as the improvement will reduce the direct consumption of energy) and the final destination of any monetary savings induced by the energy efficiency improvement. If new disposable income is spent on the consumption of goods and services with high backward linkage coefficients in terms of energy $\left(F_{g i}\right),{ }^{7}$ the direct plus indirect rebound effect will then be high. In contrast, if the additional income is mainly allocated to the acquisition of goods and services with low backward linkage coefficients in terms of energy, the resulting indirect rebound effect will be low. The best and the worst-case scenarios from improved energy efficiency in households can be built for any economy.

\footnotetext{
${ }^{7}$ The definition of these coefficients is in section 3 .
} 
Table 1. Energy consumption and backward linkage coefficients in terms of electricity consumption in Catalonia, 2005. 


\begin{tabular}{|c|c|c|c|}
\hline $\begin{array}{l}\text { Order in } \\
\text { TIOC-05 }\end{array}$ & Sector & $\begin{array}{l}\text { Total energy } \\
\text { consumption } \\
\text { (MWh) }\end{array}$ & $\begin{array}{c}\text { Backward linkage } \\
\text { coefficients } \\
\text { (MWh/thousands } € \text { ) }\end{array}$ \\
\hline 27 & Transport services by rail & $325,215.43$ & 1.576 \\
\hline 10 & Iron and casting & 69.79 & 1.553 \\
\hline 3 & Extraction of oil and gas & 34.23 & 1.021 \\
\hline 2 & Extraction and agglomeration of coal & 34.05 & 1.015 \\
\hline 14 & $\begin{array}{l}\text { Ceramic products, tiles, bricks and clay products for } \\
\text { construction }\end{array}$ & $3,968.86$ & 0.837 \\
\hline 6 & Oil refineries & $54,493.96$ & 0.722 \\
\hline 12 & Glass and glass products & $1,150.72$ & 0.597 \\
\hline 9 & Other minerals (excluding energy products) & $3,145.58$ & 0.528 \\
\hline 13 & Cement, lime and plaster & $3,626.89$ & 0.503 \\
\hline 23 & Paper and cardboard and products & $30,676.10$ & 0.466 \\
\hline 7 & Production and distribution of electricity & $213,777.17$ & 0.408 \\
\hline 15 & Chemicals and petrochemicals & $132,624.13$ & 0.375 \\
\hline 25 & Rubber and plastic products & $6,901.72$ & 0.363 \\
\hline 21 & Textiles, clothing, leather and footwear & $71,004.42$ & 0.307 \\
\hline 11 & Non-ferrous metallurgic & 12.54 & 0.279 \\
\hline 1 & $\begin{array}{l}\text { Agriculture, animal husbandry, hunting, forestry, } \\
\text { fishing }\end{array}$ & $70,321.32$ & 0.193 \\
\hline 20 & Food, beverages and tobacco & $471,264.12$ & 0.191 \\
\hline 29 & Hospitality & $3,025,082.00$ & 0.167 \\
\hline 22 & $\begin{array}{l}\text { Wood, cork and wood and cork products (except } \\
\text { furniture); articles of basketry and wickerwork }\end{array}$ & $5,858.42$ & 0.162 \\
\hline 16 & Machinery and metal processing & $19,320.20$ & 0.136 \\
\hline 31 & Administration and other public services & $1,233,629.30$ & 0.127 \\
\hline 24 & Products of edition, printed and recorded material & $27,464.18$ & 0.116 \\
\hline 8 & Gas factories - gas distribution & $14,030.35$ & 0.114 \\
\hline 17 & Shipbuilding and repair & $2,588.15$ & 0.110 \\
\hline 19 & Construction of other means of transport & $2,363.83$ & 0.101 \\
\hline 30 & Commercial activities and services & $3,652,990.69$ & 0.099 \\
\hline 18 & Motor vehicles, trailers and semitrailers & $17,357.08$ & 0.096 \\
\hline
\end{tabular}




\begin{tabular}{|clcc|}
\hline 26 & Construction & $50,057.35$ & 0.059 \\
\hline 28 & Other transport companies & $270,764.16$ & 0.054 \\
\hline 4 & Nuclear and other energies & $8,627.18$ & 0.039 \\
\hline 5 & Coke manufactures & $1,372.37$ & 0.018 \\
\hline
\end{tabular}

Source: own calculations based on input-output tables for Catalonia in 2005 and energy balances from the Spanish Ministry of Industry, Tourism and Trade.

Table 1 shows backward linkage coefficient of different economic sectors for the Catalan economy. It can be seen how they are particularly high for some sectors like: extraction and agglomeration of coal, extraction of oil and gas, iron and casting and transport services by rail. Increases in final demand of these generate a high direct and indirect energy consumption of the overall economic system. Differences between backward linkage coefficients are because of the existent interindustry relationships in the Catalan economy shown in input-output tables and the direct energy consumption of each economic sector. The combination of these two factors generates different coefficients as shown with more detail in equation (6). In summary, high economic interaction with sectors that have a high direct use of energy leads to high backward linkage coefficients.

\subsection{Structural analysis of the relationship between economic structure and the rebound effect}

A sensitivity analysis of the effect of different levels of energy efficiency improvements on the total energy consumption generated by the economic structure was conducted for the model for Catalonia. In order to compare the results, the most likely scenarios outlined by Freire-González (2011) were also used in the simulations. So, in addition to described scenarios in section 4.2, we have included three more scenarios: ${ }^{8}$

\footnotetext{
${ }^{8}$ For more detail and a formal description of these additional scenarios see Freire-González (2011).
} 
- 'Reference' scenario: This is the baseline scenario in the development of the theoretical calculation of the rebound effect. This scenario only reflects the reduction in spending on electricity sector in households, excluding the subsequent increase in the own consumption of electricity or any subsequent re-expenditure of monetary savings achieved.

- 'Income elasticities' scenario: This scenario redistributes the achieved monetary savings due to improved efficiency in the use of energy in households as a function of the incomeelasticities of the demand for each sector.

- 'Proportional' scenario: This scenario redistributes the monetary savings due to the improved energy efficiency considering the share of the expenditure by households in each sector over the total expenditures.

Figure 1 shows the variation in total energy consumption of the economy in different scenarios, given different levels of energy efficiency improvements for electricity use in households. 


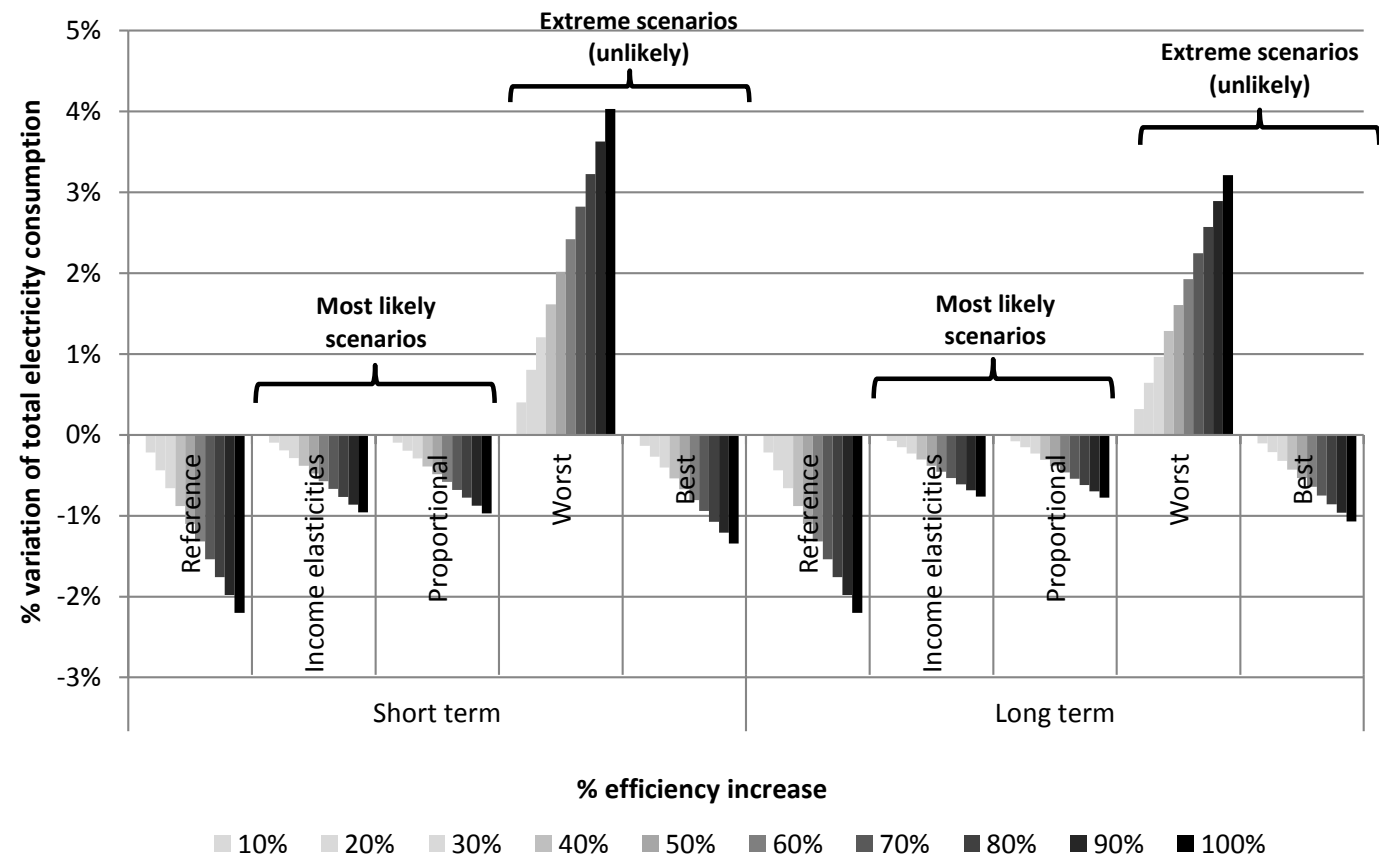

Fig. 1. Variation of the total electricity consumption in the Catalan economic structure for different percentages of electricity efficiency improvements in households in Catalonia, 2005. Source: own elaboration.

Figure 1 tries to synthesize the results in terms of variation in electricity consumption under the 5 scenarios considered: 'reference', 'income elasticities', 'proportional', 'worst' and 'best'. Moreover, within each scenario we considered different possibilities with respect to changes in energy efficiency. We can observe that these changes were proportional, and so are the results in terms of energy consumption. If there is a notable improvement in electricity efficiency in households, the best results in terms of a reduction in energy consumption generated by productive sectors are obtained in the reference scenario (initially expected results, without considering the rebound effect) and also in the best, the income elasticities, and the proportional scenarios. In these cases, the overall reduction in electricity consumption in productive sectors would be high. In contrast, in the worst case scenario there is an increase in the overall electricity consumption. Sectors that are more responsible for the differences between scenarios are those with high backward linkage coefficients in all cases: transport services by rail, iron and casting, extraction of oil and gas, and extraction and agglomeration of coal (see Table 1). However, 
depending on the re-spending scenario, there are some possible reallocations of monetary savings that would affect those sectors at the top of the table more (this would be the case in the worstcase scenario and, somehow, the income elasticities scenario) and there are other potential reallocations that would affect those sectors with low coefficients more (like the best-case scenario).

In general, it can be extracted that the greater the energy efficiency improvements in households, the greater the variability in the results obtained in terms of total electricity consumption in the productive sectors of the economy. This is because in those cases there are more monetary savings that can be reallocated.

It is also important to consider that, from this perspective, an energy efficiency improvement in households can increase the energy consumption of the overall economic structure. This would have implications on energy policy, since there could be different compositions of the energy sources between households and sectors, with different trade balances, etc.

\subsection{Structural analysis of the relations between the two types of rebound effect}

This section will discuss a sensitivity analysis that was performed using different price elasticities for the demand of electricity in order to obtain estimates of the indirect rebound effect from the model - i.e., what would the effect would be of different estimations of the direct rebound effect on the indirect rebound effect from different scenarios. 
Figure 2 shows the indirect rebound effect for electricity consumption in Catalonia, in relation to the price elasticity of the demand for electricity (we assume it is the direct rebound effect) ${ }^{9}$ under the considered re-spending scenarios (see definitions of best and worst-case scenarios in section $4.2)$.

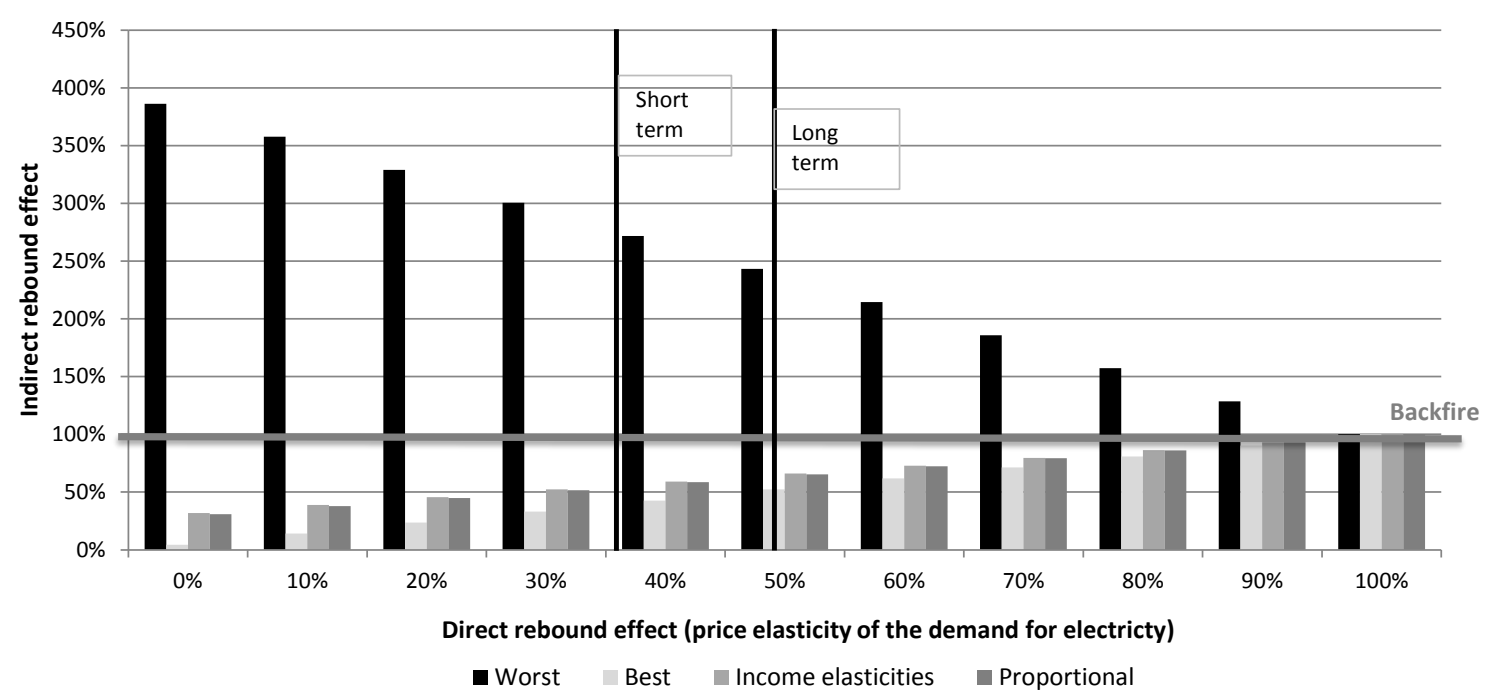

Fig. 2. Direct plus indirect rebound effect of electricity consumption in households, depending on different price elasticities for the demand of electricity in households, in Catalonia in 2005.

We can see in Figure 2 that, using a Leontief production framework, the indirect rebound effect is more variable for low price elasticities of demand for electricity. The direct rebound effect here represents the increase in the demand for electricity after an efficiency improvement in households, while the indirect rebound effect represents the total increase in the electricity consumption of the economic system needed to satisfy the increased demand for other goods and services due to the re-spending effect.

\footnotetext{
${ }^{9}$ Following Khazzoom (1980), Greene et al. (1999), Berkhout et al. (2000), Binswanger (2001), Dimitropoulos and Sorrell (2006), and Sorrell (2007), among others.
} 
Considering the scenario where there is a price elasticity for the demand of electricity with a value of zero, in the worst-case scenario (all savings allocated to the sector with the highest backward linkage coefficients), the direct plus indirect rebound effect could reach the value of $386.29 \%$ for the Catalan economic structure. For the same elasticity, in the best-case scenario, the total rebound effect would be $4.46 \%$.

As the price elasticity of the demand for electricity approaches the value of 1 (a direct rebound of $100 \%$ ) uncertainty diminishes, since there is less monetary savings to spend on other goods and services, and, therefore, the direct plus indirect rebound effect also tends towards $100 \%$, irrespective of the re-spending scenario.

As noted, although the extreme scenarios would not be realistic for any real macroeconomic context, the consideration of these findings gains significance when conducting direct rebound effect estimates in households in a given economy. It shows that low estimates of the direct rebound effect could potentially lead to higher estimates of the direct plus indirect rebound effect, depending on the production structure, the productive technology, and the structure and composition of the sectorial energy consumption of the economies.

The linearity in the results is due to the implicit fixed proportion inputs of the production functions behind the input-output modelling methodology, so the substitution effects are not taken into account (Chitnis et al., 2013). The convergence towards the same direct plus indirect rebound effect of all scenarios, as the price elasticity for the demand of electricity in households increases (the direct rebound effect), is due to the fact that smaller monetary savings are left to be spent in other economic sectors, limiting the re-spending effect. Moreover, the use of other methodologies with an explicit consideration of external sector can also affect the values of energy coefficients. Manresa and Sancho (2004) used a SAM analysis for Catalonia, found an increase of energy coefficients when completing the circular flow of income with all the components of final demand 
(including imports and exports). These authors found larger energy multipliers (an average variation of 0.51 for all economic sectors and energy sources) when they took into account government consumption, gross capital formation and exports as endogenous accounts in the model. A crucial aspect of our model is that final consumption of households and other final demand components are considered exogenous; however the consideration of external sector and other more realistic assumptions would provide more accurate values of energy coefficients. A multiregional input-output framework would be an adequate framework to see the potential effect of external sector in them. Unfortunately, we have not found a study like this for Catalonia.

\section{CONCLUSIONS}

The present research has analysed the indirect effects of an efficiency improvement in electricity use in households from a structural perspective using an input-output framework with Leontief production functions. This does not include the effects of the energy efficient improvement on productivity and economic growth or the effects of efficiency improvements on other agents or economic sectors.

As stated in the introduction, the aim of this research was to understand the way in which the configuration of the economic structure can affect the energy savings derived from energy efficiency in households in a Leontief production framework. We found that, for low estimations of the direct rebound effect, the indirect rebound effect has a wider range of values that should be analysed depending on the economic context - which could lead from low to high rebounds. On the other hand, high estimates of the direct rebound effect yield less variability of the indirect rebound effect, converging to a direct and indirect rebound of $100 \%$. To prove this, the hybrid model used in this research combines econometric, input-output, and re-spending models. Extreme cases reflect the potential direct plus indirect rebound of a Leontief production structure. 
However, they would be unlikely to occur at the aggregate level, although they could occur in a particular area at a microeconomic level.

These findings add more elements to the discussion provided by much of the empirical literature on the direct rebound effect for energy services in households. The literature has suggested that low estimations of the direct rebound effect (values less than 30\%) have no significant effect on energy consumption, and therefore that no corrective measures are necessary to address it. In contrast, the findings indicate that, depending on the economic context, low estimations of the direct rebound effect should be accompanied by additional measures to prevent an increase in the consumption of goods and services with high energy content (Freire-González and Puig-Ventosa, 2015; Font Vivanco et al., 2016). However, other production frameworks should be analysed and compared. This research shows some additional valuable results: the maximum direct and indirect rebound effect that the Catalan economy could reach would be of $386.29 \%$, if all monetary savings from efficiency improvements in electricity in households were spent on transport services by rail (the sector with the highest backward linkage coefficient). The minimum direct and indirect rebound effect that the Catalan economy could reach would be of $4.46 \%$, if those savings were spent on coke manufacturing (the sector with the lowest backward linkage coefficient). However, a re-spending scenario based on a proportional reallocation of new income amongst all economic sectors - the most realistic scenario of the three - would lead to direct and indirect rebound effects lower than $100 \%$ in all cases. So, a combined rebound effect higher than 100\% (backfire) would be unlikely for the Catalan economy.

Although policy-related propositions usually require more robust and holistic results from a number of approaches and methodologies, the findings and simulations conducted with the extreme scenarios could be important when designing policy measures to tackle the rebound effect, such as taxes, since the way they are designed and the way the revenues from those taxes are spent would affect the rebound effect in different ways. It is also important when planning energy policies, since the indirect rebound effect produces unexpected changes in energy 
consumption. If the rebound effect is not considered when designing energy efficiency policies, energy efficiency measures will not be as effective as expected.

Further research needs to expand on the proposed framework in order to obtain the indirect rebound effects of efficiency improvements to production processes in different economic sectors, by modifying technical coefficients in input-output matrices and then obtaining new energy intensity coefficients $(F)$ that are suited to the 'real savings' part of equations (25) and (26). Modelling can also be improved by adding imports to the analysis - by using multiregional models, etc.

Indirect energy requirements resulting from improved energy efficiency in households could be larger than the direct savings from those improvements. One of the main contributions of this research is that it points to the need to take action, even when the direct rebound effect is low.

\section{ACKNOWLEDGEMENTS}

We would like to acknowledge the Comissionat per a Universitats i Recerca del Departament

d'Innovació, Universitats i Empresa (Generalitat de Catalunya), and ENT Environment and Management for funding this research.

\section{REFERENCES}

Alcántara, V., 1995. Economía y contaminación atmosférica: hacia un nuevo enfoque desde el análisis Input-output. Doctoral thesis. Universitat de Barcelona.

Alfredsson, E.C., 2004. 'Green' consumption - no solution for climate change. Energy 29, 513524. 
Ayres, R.U., Ayres, L.W., Warr, B., 2003. Exergy, power and work in the US economy, 19001998. Energy 28, 219-273.

Berkhout, P.H., Muskens, J.C., Velthuijsen, J. W., 2000. Defining the rebound effect. Energy Policy 28, 425-432.

Binswanger, M., 2001. Technological progress and sustainable development: what about the rebound effect? Ecological Economics 36(1), 119-132.

Brookes, L.G., 1979. A low energy strategy for the UK, by G. Leach et al.: a review and reply. Atom 269, 3-8.

Bullard, C.W., Herendeen, R.A., 1975. The energy cost of goods and services. Energy Policy 34, $268-278$.

Carlsson-Kanyama, A., Engstrom, R., Kok, R., 2005. Indirect and direct energy requirements of city households in Sweden. Journal of Industrial Ecology 91(2), 221-236.

Carpintero, O., Sastre, S., Lomas, P., Arto, I., Bellver, J., Delgado, M., Doldán, X., Fernández, J., Frías, J., Ginard, X., González, A.C., Gual, M., Murray, I., Naredo, J.M., Ramos, J., Velázquez, E., Villasante, S. 2014. El metabolismo económico regional español, Madrid: FUHEM Ecosocial.

Casals, X.G., 2006. Analysis of building energy regulation and certification in Europe: their role, limitations and differences. Energy and Buildings 38, 381-392.

Casler, S., Wilbur, S., 1984. Energy input-output analysis, a simple guide. Resources and Energy $6,187-201$.

Cellura, M., Guarino, F., Longo, S., Mistretta, M., Orioli, A., 2013. The role of the building sector for reducing energy consumption and greenhouse gases: an Italian case study. Renewable energy $60,586-597$.

Chapman, P., 1974. Energy costs: a review of methods. Energy Policy 2, 91-103.

Chitnis, M., Sorrell, S., Druckman, A., Firth, S., Jackson, T., 2012. Estimating direct and indirect rebound effects for UK households. Sustainable Lifestyles Research Group: Working Paper, 01-12. 
Chitnis, M., Sorrell, S., Druckman, A., Firth, S.K., Jackson, T., 2013. Turning lights into flights: estimating direct and indirect rebound effects for UK households. Energy Policy 55, 234250.

Cohen, C., Lenzen, M., Schaeffer, R., 2005. Energy requirements of households in Brazil. Energy Policy 33, 555-562.

Davis, L. W., 2007. Durable goods and residential demand for energy and water: evidence from a field trial. Working Paper, Department of Economics, University of Michigan.

Dimitropoulos, J., 2007. Energy productivity improvements and the rebound effect: An overview of the state of knowledge. Energy Policy 35(12), 6354-6363.

Dimitropoulos, J., Sorrell, S., 2006. The Rebound effect: Microeconomic Definitions, Extensions and Limitations. Proceedings of the 29th IAEE International Conference, Potsdam, Germany.

Druckman, A., Chitnis, M., Sorrell, S., Jackson, T., 2010. An investigation into the rebound and backfire effects from abatement actions by UK households. Working Paper Series 05-10, University of Surrey.

Feist, W., 1996. Life-cycle energy balances compared: low energy house, passive house, selfsufficient house. Proceedings of the International Symposium of CIB W67, Vienna, Austria.

Font Vivanco, D., Freire-González, J., Kemp, R., van der Voet, E., 2014. The remarkable environmental rebound effect of electric cars: a microeconomic approach. Environmental Science \& Technology 48, 12063-12072.

Font Vivanco, D., van der Voet, E., 2014. The rebound effect through industrial ecology's eyes: a review of LCA-based studies. The International Journal of Life Cycle Assessment 19, 1933-1947.

Font Vivanco, D. Kemp, R., van der Voet, E., 2016. How to deal with the rebound effect? A policy-oriented approach. Energy Policy 94, 114-125. 
Fouquet, R., Pearson, P., 2006. Seven centuries of energy service: the price and use of light in the United Kingdom 1300-2000. The Energy Journal 27(1), 139-176.

Freire-González, J., 2010. Empirical evidence of direct rebound effect in Catalonia. Energy Policy 38(5), 2309-2314.

Freire-González, J., 2011. Methods to empirically estimate direct and indirect rebound effect of energy-saving technological changes in households. Ecological Modelling 223 1, 32-40.

Freire-González, J., Puig-Ventosa, I., 2015. Energy Efficiency Policies and the Jevons Paradox. International Journal of Energy Economics and Policy 5(1), 69-79.

Frondel, M., Peters, J., Vance, C., 2007. Identifying the rebound: issues and empirical evidence from a German household panel. RWI Discussion Papers No. 57 Essen.

Greene, D.L., Kahn, J.R., Gibson, R. C., 1999. Fuel economy rebound effect for US household vehicles. Energy Journal 203, 1-31.

Greening, L.A., Greene, D. L., 1998. Energy use, technical efficiency, and the rebound effect: a review of the literature. Report to the U.S. Department of Energy. Denver: Hagler Bailly and Co.

Greening, L.A., Greene, D.L., Difiglio, C., 2000. Energy efficiency and consumption - the rebound effect - a survey. Energy Policy 28, 389-401.

Grubler, A., 2003. Technology and global change. Cambridge, UK: Cambridge University Press

Guertin, C., Kumbhakar, S., Duraiappah, A., 2003. Determining demand for energy services: investigating income-driven behaviours. Winnipeg. International Institute for Sustainable Development.

Herendeen, R., Tanaka, J., 1976. The energy cost of living. Energy 12, 165-78.

Herring, H., 1999. Does energy efficiency save energy? The debate and its consequences. Applied Energy 63, 209-226.

Hinterberger, F., Schmidt-Bleek, F., 1999. FORUM: Dematerialization, MIPS and Factor 10. Physical sustainability indicators as a social device. Ecological Economics 29(1), 53-56.

Idescat, 2007. Les Taules Input-output de Catalunya 2001. Generalitat de Catalunya, Barcelona. 
Jalas, M., 2002. A time use perspective on the materials intensity of consumption. Ecological Economics 41(1), 109-123.

Jenkins, J., Nordhaus, T., Shellenberger, M., 2011. Energy emergence: rebound and backfire as emergent phenomena. Breakthrough Institute, Oakland, CA, USA.

Jevons, W.S., 1865. The Coal Question. London: Macmillan and Co.

Joshi, S., 1999. Product environmental life-cycle assessment using input-output techniques. Journal of Industrial Ecology 3, 95-120

Kaufmann, R.K., Azary-Lee, I.G., 1990. A biophysical analysis of substitution: does substitution save energy in the US forest products industry?, Ecological economics: its implications for forest management and research. Proceedings of a Workshop held in St Paul, Minnesota, April 2-6.

Kemp, R., 1994. Technology and the transition to environmental sustainability: the problem of technological regime shifts. Futures 26(10): 1023-1046.

Khazzoom, J.D., 1980. Economic implications of mandated efficiency standards for household appliances. Energy Journal 1, 21-39.

Kok, R., Benders, R.M.J., Moll, H.C., 2006. Measuring the environmental load of household consumption using some methods based on input-output energy analysis: a comparison of methods and a discussion of results. Energy Policy 34(17), 2744-61.

Lenzen, M., Pade, L., Munksgaad, J., 2004. CO2 multipliers in multi-region input-output models. Economic Systems Research 16, 391-412.

Leontief, W., 1970. Environmental repercussions and the economic structure: an input-output approach. Review of Economics and Statistics 52, 262-271.

Leontief, W., Ford, D., 1971. Air pollution and the economic structure: empirical results of inputoutput calculations. Fifth International Conference on Input-output Techniques, Geneva, Switzerland, North Holland Pub. Co.

Lovins, A.B., 1977. Soft Energy Paths: Toward a Durable Peace. Penguin Books. 
Lovins, A.B., Henly, J., Ruderman, H., Levine, M. D., 1988. Energy saving resulting from the adoption of more efficient appliances: another view; a follow-up. The Energy Journal 92, 155.

Lovins, L.H, Lovins, A.B., 2001. Natural capitalism: path to sustainability? Corporate Environmental Strategy 8(2), 99-108.

Manresa, A., Sancho, F., 2004. Energy intensities and CO2 emissions in Catalonia: a SAM analysis. International Journal of Environment, Workplace and Employment, 1(1), 91106.

Miller, R.E., Blair, P.D., 2009. Input-Output Analysis: Foundations and Extensions, 2nd ed. Cambridge, Cambridge University Press.

Mizobuchi, K., 2008. An empirical study on the rebound effect considering capital costs. Energy Economics 30(5), 2486-2516.

Murray, C.K., 2013. What if consumers decided to all 'go green'? Environmental rebound effects from consumption decisions. Energy Policy 54, 240-256.

Nässén, J., Holmberg, J., 2009. Quantifying the rebound effects of energy efficiency improvements and energy conserving behaviour in Sweden. Energy Efficiency 2, 22012231.

Nesbakken, R., 2001. Energy consumption for space heating: a discrete-continuous approach. Scandinavian Journal of Economics 103(1), 165-84.

Proops, J.L.R., 1988. Energy intensities, input-output analysis \& economic development, in: Ciaschini, M. (Ed.), Input-Output Analysis: current developments. Chapman \& Hall.

Royal Commission on Environmental Pollution, 2007. The Urban Environment, Twenty-sixth Report, Cm 7009, London: TSO.

Ruzzenenti, F., Basosi, R., 2008. The rebound effect: an evolutionary perspective. Ecological Economics 67, 526-537.

Sartori, I., Hestnes, A.G., 2007. Energy use in the life-cycle of conventional \& low-energy buildings: a review article. Energy and Buildings 39, 249-57. 
Saunders, H.D., 1992. The Khazzoom-Brookes Postulate \& neoclassical growth. The Energy Journal 13(4), 131-148.

Saunders, H.D., 2008. Fuel conserving (and using) production functions. Energy Economics 30, $2184-2235$.

Saunders, H.D., Tsao, J.Y., 2012. Rebound effects for lighting. Energy Policy 49(0): 477-478.

Schipper, L., Grubb, M., 2000. On the rebound? Feedback between energy intensities and energy uses in IEA countries. Energy Policy 28(6-7), 367-88.

Sorrell, S., 2007. The rebound effect: an assessment of the evidence for economy-wide energy savings from improved energy efficiency. UK Energy Research Centre.

Suh, S., Huppes, G., 2005. Methods for life cycle inventory of a product. Journal of Cleaner Production 13, 687-697.

Takase, K.Y., Kondo, K., Washizu, A., 2005. An analysis of sustainable consumption by the waste input-output model. Journal of Industrial Ecology 9(1-2), 201-219.

Thomas, B.A., 2011. Estimating the US economy-wide rebound effect. IAEE Conference, 19-23 June 2011. Stockholm, Sweden.

Thomas, B.A., Azevedo, I.L., 2013a. Estimating direct and indirect rebound effects for U.S. households with input-output analysis. Part 1: theoretical framework. Ecological Economics 86, 199-210.

Thomas, B.A., Azevedo, I.L., 2013b. Estimating direct and indirect rebound effects for U.S. households with input-output analysis. Part 2: simulation. Ecological Economics 86, $188-198$.

van den Bergh, J.J.M., 2011. Energy conservation more effective with rebound policy. Environmental Resource Economics 48, 43-58.

von Weizsäcker, E.U. (1994). Sustainable economy. Science of The Total Environment 143(1), $149-156$

Wang, H., Zhou, D.Q., Zhou, P., Zha, D.L., 2012. Direct rebound effect for passenger transport: empirical evidence from Hong Kong. Applied Energy 92, 162-167. 
West, S.E., 2004. Distributional effects of alternative vehicle pollution control policies. Journal of Public Economics 88, 735-57.

Wigley, K.J., 1997. Assessment of the importance of the rebound effect. Paper presented at the 18th North American Conference of the USAEE/IAEE, San Francisco.

Winther, B.N., Hestnes, A.G., 1999. Solar versus Green: the analysis of a Norwegian row house. Solar Energy 66(6), 387-93.

Yu, B., Zhang, J., Fujiwara, A., 2013. Evaluating the direct and indirect rebound effects in household energy consumption behavior: a case study of Beijing. Energy Policy 57(0), $441-453$. 